\title{
Power Quality Improvement using D-STATCOM with Instantaneous Symmetrical Component Theory
}

\author{
K. Srinivas, Ajay Uradi
}

\begin{abstract}
A technique is introduced to improve the voltage sag under sudden changes in load. The proposed technique is implemented by D-STATCOM (Distribution static compensator) and it is controlled by ISCT (Instantaneous Symmetrical Component Theory). Due to sudden changes in load, the voltage dip occurs at the time of switching of loads. At this time, the control technique generates reference currents and hysteresis block compares these currents with the reference currents and generates the pulses to D-STATCOM. Implementation of system along with compensation is carried out in MATLAB/SIMULINK
\end{abstract}

Keywords: D-STATCOM, ISCT, voltage sag.

\section{INTRODUCTION}

Voltage sag is one of the major problems in Power Quality issues. The Power System is a combination of number of loads that are connected to the generation station through transmission and distribution system. Many disturbances are occurs in power system like voltage swell, voltage sag, glitches, transients, sudden surges etc [1]. These disturbances will effects on the quality of power. In recent years power quality is major issue for the customers. To improve the power quality, so many technique are there viz., DSTATCOM, SVC, UPQC, DVR etc. Among these D-STATCOM is more efficient and powerful tool for improving the power quality. Due to sudden changes in several loads (In this paper two loads are considered) the voltage dips are occur in system.

Hence to mitigate this, one technique is required at distribution level. This paper presents the, improving of voltage sag under sudden changes in load. The control of D- STATCOM is achieved by using instantaneous symmetrical component theory. This technique is helpful for the improvement of power quality and supply to the customers. This system with D-STATCOM is simulating in MATLAB. The result establishes the proposed technique is efficient to improve the voltage sag.

Revised Manuscript Received on April 13, 2020.

* Correspondence Author

Dr K. Srinivas*, Assistant Professor and Head Department of Electrical and Electronics Engineering, Jawaharlal Nehru Technological University Hyderabad College of Engineering Jagtial.

Ajay Uradi, M.Tech in Electrical Power Systems, Jawaharlal Nehru Technological University Hyderabad College of Engineering Jagtial.

(C) The Authors. Published by Blue Eyes Intelligence Engineering and Sciences Publication (BEIESP). This is an open access article under the CC BY-NC-ND license (http://creativecommons.org/licenses/by-nc-nd/4.0/)

\section{DESIGN OF D-STATCOM}

D-STATCOM is a distribution static compensator connected in shunt with system to compensate the voltage sag, swell, glitches etc [2]. D-STATCOM mainly contains VSI and in parallel with the capacitor.VSI is controlled by the one of the technique that will contribute to mitigate the power quality problem [4].

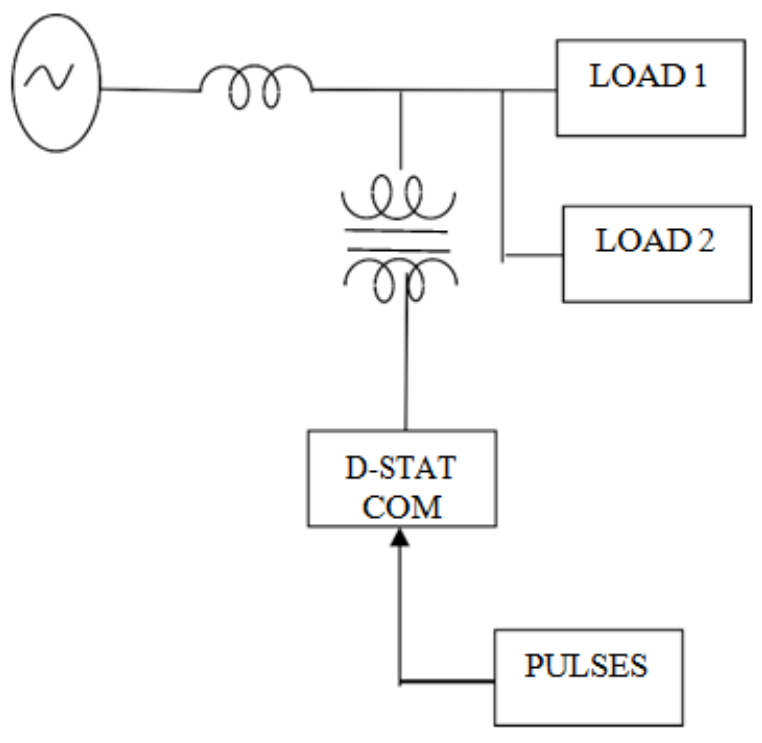

Fig.1. Block diagram of D-STATCOM

Basic diagram of D-STATCOM is as shown in above fig 1. Basically D-STATCOM contains VSI, coupling transformer, capacitor and control algorithm incorporated in it [5]. The capacitor is used for storage purpose and reactive power support. In this paper D-STATCOM controlled by Instantaneous Symmetrical Component Theory.

\section{CONTROL ALGORITHM}

The control technique Instantaneous Symmetrical Component Theory is introduced by Fortescue for compensate the voltage and currents in unbalanced system [3].

\section{A. Instantaneous Symmetrical Component Theory:}

Reference current to the control of D-STATCOM is calculated by this theory.

Published By:

Blue Eyes Intelligence Engineering
$\&$ Sciences Publication

(c) Copyright: All rights reserved.

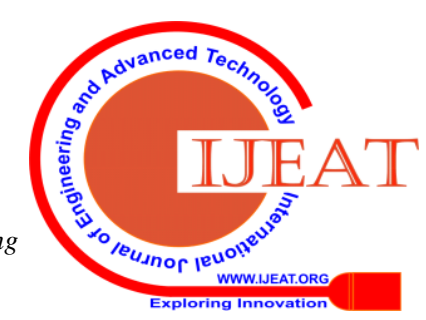


According to this theory reference currents are generated from the average power of source and compare with the currents with load currents to get reference currents. Vsa, Vsb, Vsc are the source currents of A phase B phase and C phase respectively. $\mathrm{P}$ avg is the average power and Ila, Ilb and Ilc are the load currents respectively. Ira, Irb and Irc are the reference currents for the D-STATCOM. Ida, Idb and Idc are the DSTATCOM currents which are injected into the system.

$$
\begin{aligned}
& V s{ }^{*} I s a+V s b^{*} I s b+V s c * I s c=P a v g \\
& \frac{V s a+(V s b-V s c) * P a v g}{V s a^{2}+V s b^{2}+V s c^{2}}=I a \\
& \frac{V s b+(V s c-V s a)^{*} P a v g}{V s a^{2}+V s b^{2}+V s c^{2}}=I b \\
& \frac{V s c+(V s a-V s b) * P a v g}{V s a^{2}+V s b^{2}+V s c^{2}}=I c \\
& I a-I l a=I r a \\
& I b-I l b=I r b \\
& I c-I l c=I r c
\end{aligned}
$$

Ira-Ida is reference current signal for A phase similarly Irb-Idb, Irc-Idc are the reference current for B and C phases respectively.

\section{B. Hysteresis Current Control:}

Hysteresis current control basically a closed loop control which is continuously monitoring the error output between the actual current and reference currents. It consists of relay and summation block to compare the I actual and Iref which is generated from the above theory. The relay circuit is given out pulses to the d-statcom it will control according to the voltage levels in the system

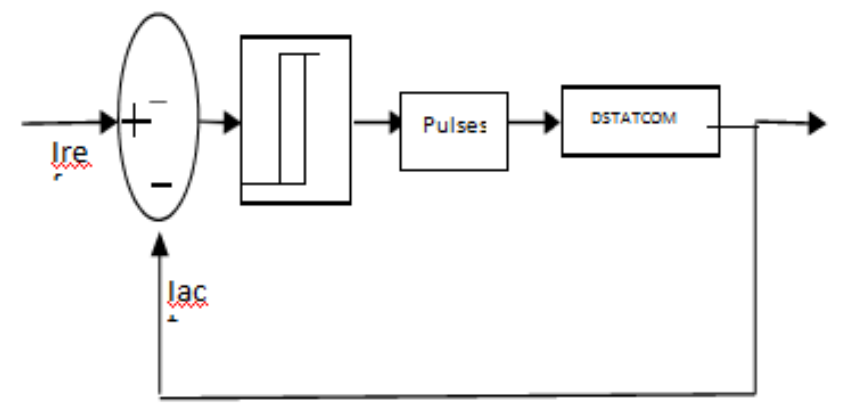

Fig.2. block diagram of hysteresis current control

\section{RESULTS AND SIMULATION}

\section{A. Simulation without D-STATCOM}

Initially one load is connected to the line, but due to Requirement suddenly another load has been added between $0.1 \mathrm{sec}$ to $0.2 \mathrm{sec}$. Due to this sudden addition of load the voltage sag occurred between $0.1 \mathrm{sec}$ to $0.2 \mathrm{sec}$.

Fig. 3 shows the simulation model of a system without DSTATCOM. It consists of two loads, the second load is added suddenly at the intervals between $0.1 \mathrm{sec}$ to $0.2 \mathrm{sec}$. At this instant of time, the voltage sag has been occurring and current is drawn from system more than normal current.

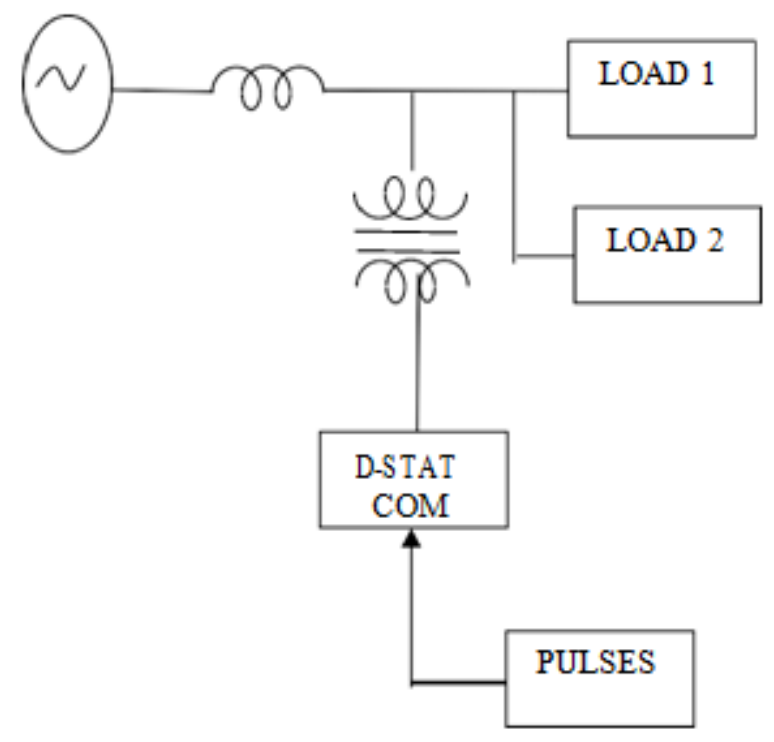

Fig.3 Simulation model without D-STATCOM

For the power quality improvement, voltage sag has to be reduced. So the D-STATCOM is added parallel to the existing system with a control scheme of instantaneous symmetrical component theory (ISCT) to mitigate the voltage sag problem. Fig. 4 shows the simulation model of a system with D- STATCOM to reduce the voltage sag problem.

Due to sudden addition of load 2, voltage sag exists in a system between the intervals of $0.1 \mathrm{sec}$ to $0.2 \mathrm{sec}$ and magnitude of voltage reduced from $330 \mathrm{~V}$ to $270 \mathrm{~V}$ shown in Fig.5.(a). In order to improve voltage sag D-STATCOM operates between 0.1sec to 0.2sec as shown in Fig.5.(b). After compensation the voltage sag is improved from $270 \mathrm{~V}$ to $315 \mathrm{~V}$ as shown in Fig.5. (c).

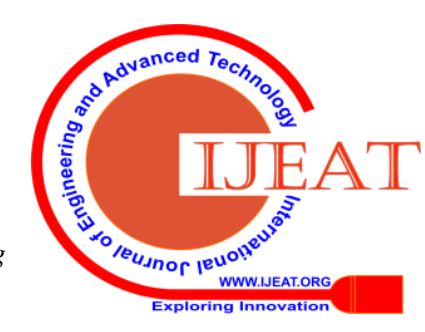




\section{B. Simulation with D-STATCOM}

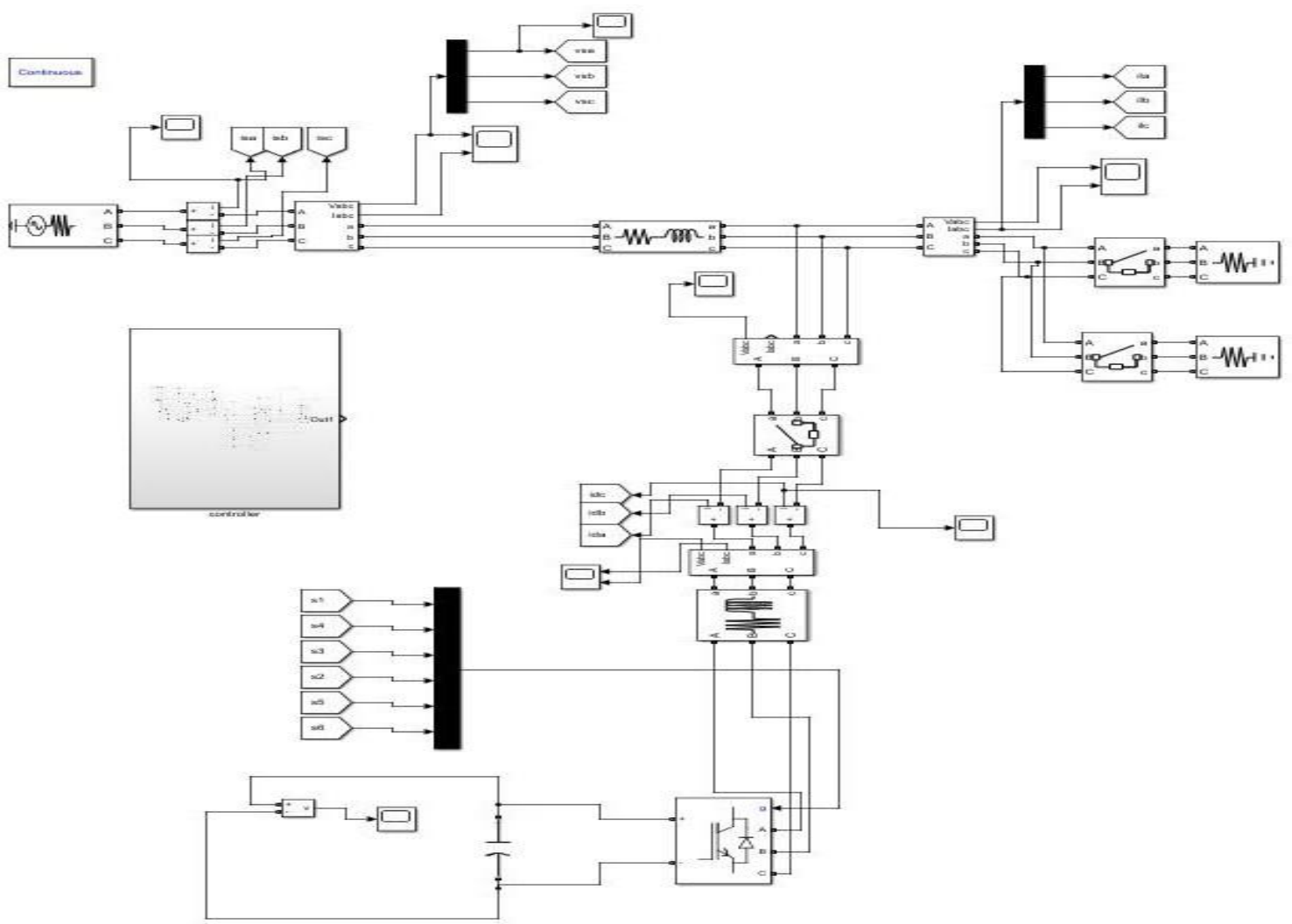

Fig.4. Simulation model with D-STATCOM

Simulation parameters: source $440 \mathrm{~V}, 50 \mathrm{~Hz}, 12 \mathrm{KVA}$ source impedance $0.89290 h m s$ LOAD 5KW, 5KW DC link Capacitor $2.2 \mathrm{nF}$.

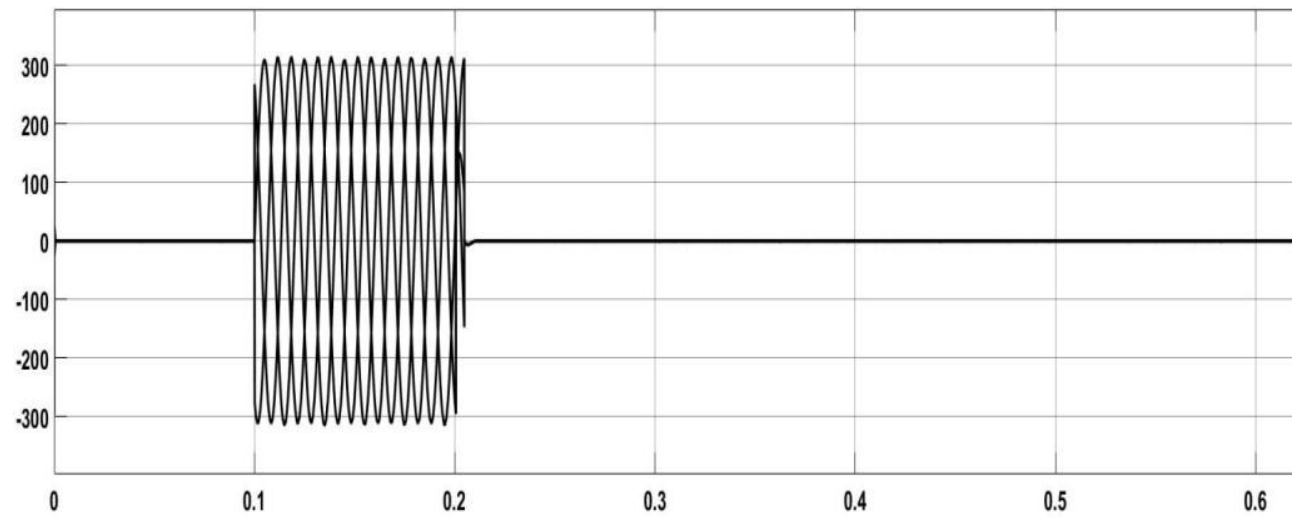

(a)

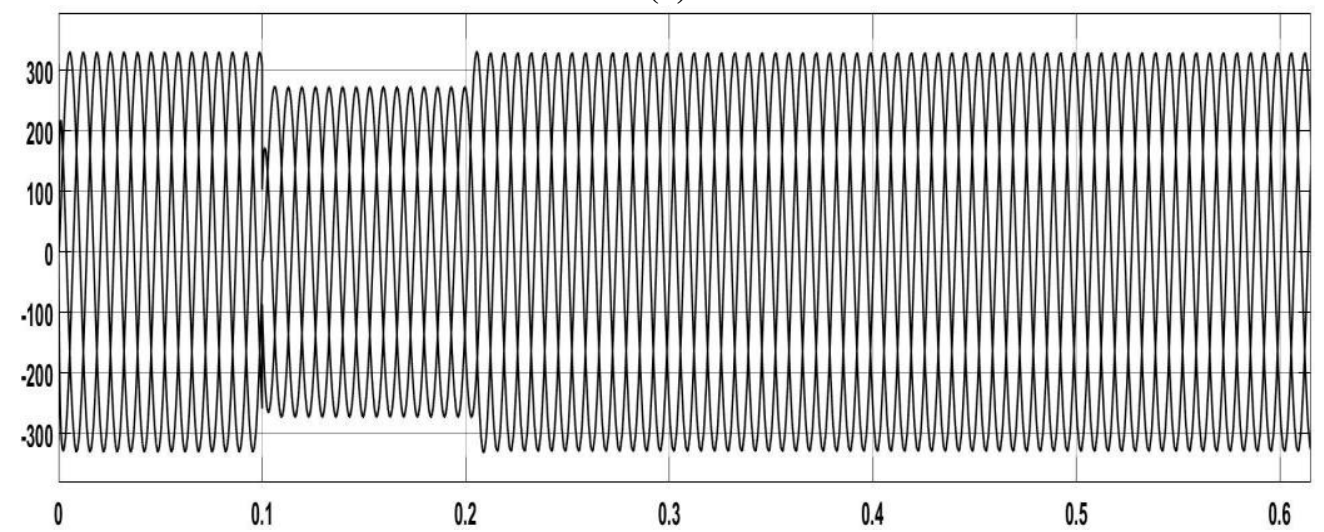

(b) 


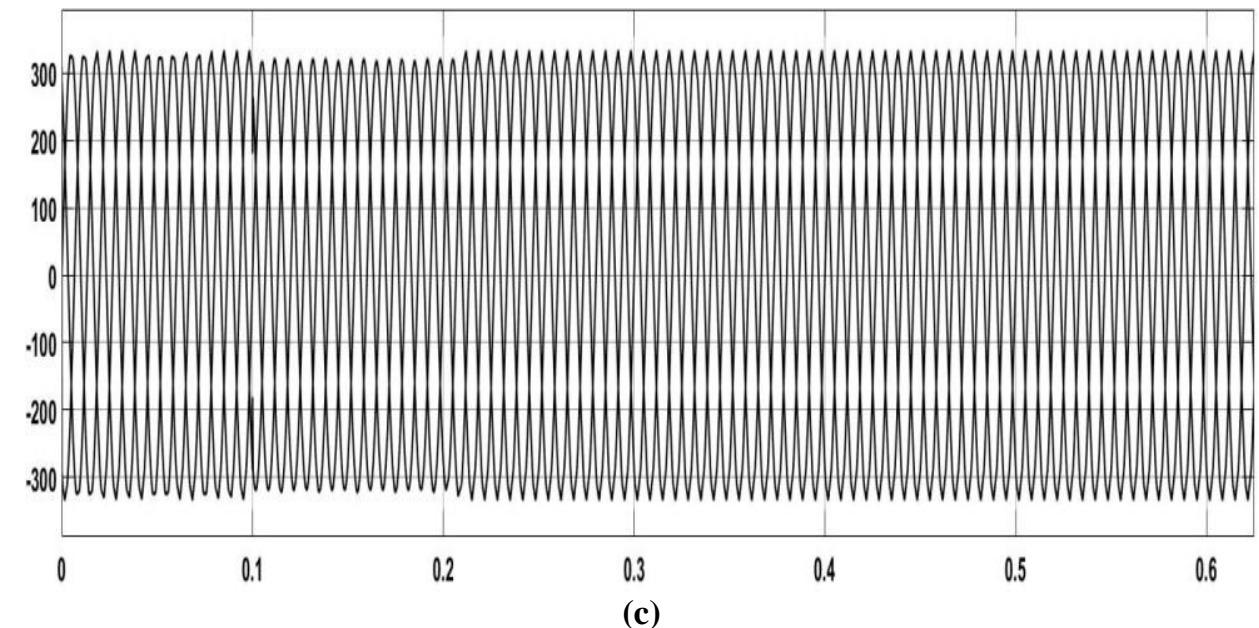

Fig.5. simulation results of (a) Load voltage waveform without D-STATCOM (b) D-STATCOM voltage waveform. (c) Load voltage waveform with D-STATCOM.

\section{CONCLUSION}

This paper concludes that, due to sudden changes in load in short duration of time ( $0.1 \mathrm{sec}$ to $0.2 \mathrm{sec})$ causes voltage dip in load voltages and sudden rises in currents. This problem mitigated by using D-STATCOM with a control scheme of instantaneous symmetrical component theory (ISCT).

\section{REFERENCES}

1. M. Bollen, Understanding Power Quality Problems. Piscataway, NJ, USA: IEEE, ch. 1, pp. 1-35, 2000.

2. K. k. Sen. and M. L. Sen., Introduction to FACTS Controllers: Theory, Modeling and Applications, IEEE Press, New Jersey, 2009.

3. B. Singh, J. Solanki, "A Comparison of Control Algorithms for DSTATCOM," IEEE Transactions on Industrial Electronics, Vol. 56, No. 7, pp. 2738-2745, July 2009

4. C. Kumar and Mahesh K. Mishra, "A voltage-controlled DSTATCOM for power-quality improvement," IEEE Trans. Power Del., vol. 29, no. 3, pp. 1499-1507, Jun. 2014.

5. M. K. Mishra, A. Ghosh and A. Joshi, "Operation of a DSTATCOM in voltage control mode," IEEE Transactions on Power Delivery, vol. 18, no. 1, pp. 258-264, Jan 2003.

\section{AUTHOR PROFILE}

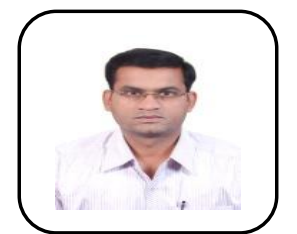

Dr K. Srinivas received the B.E. degree in Electrical and Electronics Engineering from Chaitanya Bharathi Institute of Technology and Science, Hyderabad, Osmania University, Hyderabad, India, in 2002, M.Tech. Degree in power systems and Power Electronics from Indian Institute of Technology, Madras, Chennai, in 2005, Ph.D from Jawaharlal Nehru Technological University Hyderabad. Currently working as an Assistant Professor and Head Department of Electrical and Electronics Engineering, Jawaharlal Nehru Technological University Hyderabad College of Engineering Jagtial. Fields of interest include power quality and power-electronics control in power systems

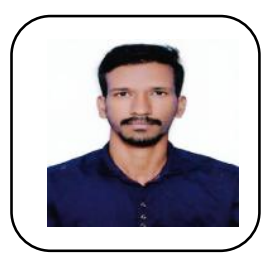

Ajay Uradi received the B.tech degree In electrical and electronics engineering From sree chaitanya institute of technological and sciences, Karimnagar, JNTU Hyderabad in 2017. currently pursuing M.Tech in Electrical Power Systems, Jawaharlal Nehru Technological University Hyderabad College of Engineering Jagtial.

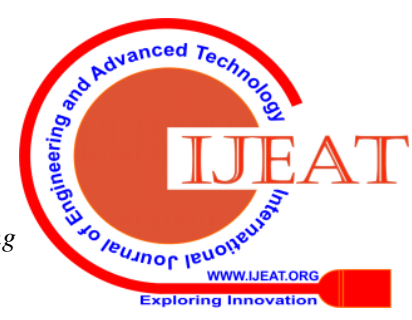

